\title{
Validation of photovoltaics powered UPQC using ANFIS controller in a standard microgrid test environment
}

\author{
Sumana $\mathbf{S}^{\mathbf{1}}$, Dhanalakshmi $\mathbf{R}^{1}$, Dhamodharan $\mathbf{S}^{\mathbf{2}}$ \\ ${ }^{1}$ Department of Electrical and Electronics Engineering, Dayananda Sagar College of Engineering, Bengaluru, India \\ ${ }^{2}$ Viswa Jothi Technologies private Ltd, Bengaluru, India
}

\begin{tabular}{l} 
Article Info \\
\hline Article history: \\
Received Mar 6, 2021 \\
Revised Jul 15, 2021 \\
Accepted Aug 6, 2021 \\
\hline
\end{tabular}

Keywords:

ANFIS controller

Microgrid

PV power UPQC

Validation of UPQC

\begin{abstract}
The power quality improvement becomes one of the important tasks while using microgrid as main power supply. Because the microgrid is combination of renewable energy resources. The renewable energy resources are intermittent in power supply and at the peak loading condition it has to supply the required power. So, the power quality problems may increase in that time. Out of all power quality issues the voltage drop and harmonic distortion is considered as the most serious one. In recent years unified power quality conditioner (UPQC) is emerged as most promising device which compensates both utility as well as customer side power quality disturbances in effective way. The compensating potentiality used in the UPQC is limited by the use of DC link voltage regulation and the conventional proportional integral (PI) controller. In this paper the compensating potentiality of the UPQC device is controlled by an adaptive neuro fuzzy inference system (ANFIS) control and it is powered from the available photovoltaics (PV) power generation. The effect of adding an intelligent UPQC is tested in the standard IEEE-14bus environment. MATLAB 2017b is used here for testing and plotting the simulation results.
\end{abstract}

This is an open access article under the CC BY-SA license.

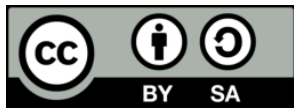

\section{Corresponding Author:}

Sumana $S$

Department of Electrical and Computer Engineering, Dayananda Sagar College of Engineering

Shavige Malleswara Hills, Kumaraswamy layout, Bengaluru-560061, India

Email: sumana-eee@dayanandasagar.edu

\section{INTRODUCTION}

The concept of microgrid is the connecting point of all the distribution side generator and the loads together. The power flow is monitored and controlled by central grid control system. The need for increase in microgrid is due to reduced cost of installation and time saver in implementation. The actual power system consists of generation, transmission and distribution. In microgrid it is only at the distribution all the three happens in miniatured way. The power quality improvement in smart grid environment is implemented in [1] using modified UPQC topology. A new algorithm for UPQC is proposed in [2]. A single-stage quasi UPQC is implemented in [3]. A new fuel cell power UPQC is implemented in [4]. The power quality issues due to the impact of electric vehicle is implemented in [5]. The power quality issues due to implementation of vehicle to grid system is implemented in [6]. The problem due to incoordination in charging of electric vehicle problem is handled in [7]-[8]. The charger with good efficiency using the sliding mode control is implemented in [9]. A recent trend in microgrid, architecture and control with AC and DC hybrid microgrids are presented in [10]-[12]. The architecture and review of AC and DC microgrid is discussed in [13]-[16]. The test beds of microgrid used around the world is given in [17] and its design is explained in [18], control and modelling are explained in [19]-[24]. Opportunities of microgrid is explained in [25]. The comparison of the DC and AC microgrid is presented in [26]. The microgrid standard test bed is implemented as simulation 
in [27]. In this paper the validation of the UPQC which is controlled with ANFIS and power by photovoltaics (PV) solar is carried out in a standard test environment. The results are presented and compared with and without UPQC.

\section{PROPOSED TEST SYSTEM}

In the Figure 1, the microgrid is integrated to the point of common coupling (PCC) to an electrical sub transmission system of $69 \mathrm{kV}, 100 \mathrm{MVA}$ with an $\mathrm{X} / \mathrm{R}$ ratio of 10 . It comprises of two voltage distribution levels: A primary $13.8 \mathrm{kV}$ voltage level, represented in blue color and a secondary $0-22 \mathrm{kV}$ voltage level represented in green color. The grid comprises of three sub MGs the description of three sub MGs is: AC microgrid-1 is connected at the $0-22 \mathrm{kV}$ level via lines 4,5 and 6 to the AC microgrid-2. It operates with a frequency of $60 \mathrm{HZ}$ and diesel generator which provides energy to 4 loads. The second sub MG is AC microgrid-2, which operates with the PV array 2 and the battery energy storage system 2 [BESS]. The operating frequency of both AC sub MGs is $60 \mathrm{~Hz}$. The DC busbar is tied to the AC microgrid-2 by way of two parallel bidirectional converters tagged 1.1 and 1.2 which functions as rectifiers or inverters to interchange active and reactive power through two transformers named TDC-1 and TDC-2 [28]. The details about the different parameters of the system is shown in Table 1.

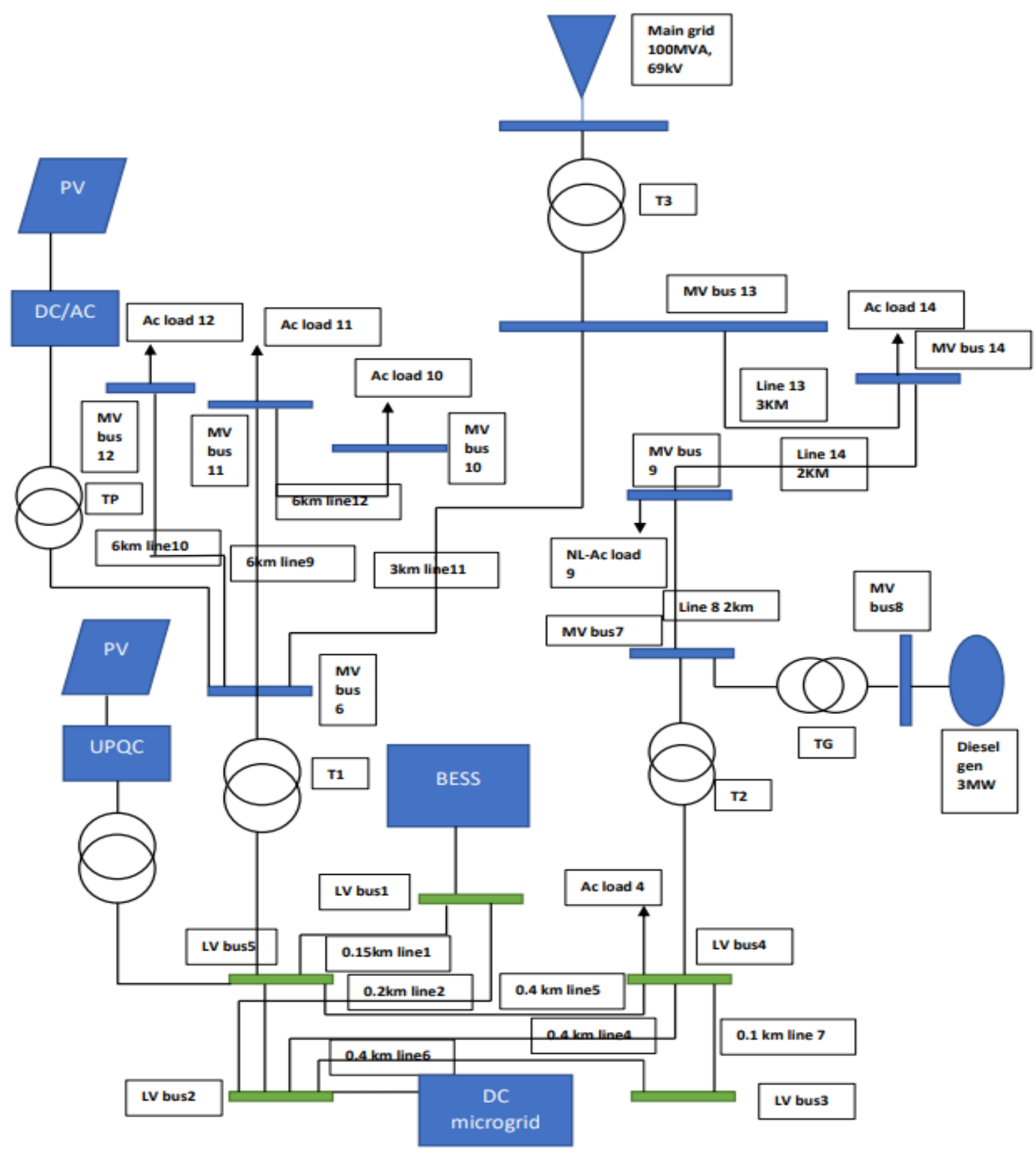

Figure 1. Proposed system 


\begin{tabular}{ccc}
\multicolumn{3}{c}{ Table 1. Parameters of proposed system } \\
\hline Equipment & Parameters & Values \\
\hline PV rating & Open circuit voltage in V & $37.2 \mathrm{~V}$ \\
& Maximum power point voltage in V & $30.2 \mathrm{~V}$ \\
Boost converter & Wattage in W & $244.62 \mathrm{~W}$ \\
& Input voltage in V & $604 \mathrm{~V}$ \\
battery specifications & Output voltage in V & $900 \mathrm{~V}$ \\
& Frequency in Hz & $50 \mathrm{kHz}$ \\
& Voltage in V & $750 \mathrm{~V}$ \\
EV Charger & Capacity in Ah & 50 \\
& Initial SOC \% & $90 \%$ \\
& Converter & Boost \\
& Inductor (L) H & $30 \mathrm{uH}$ \\
EV battery & Capacitor (C) F & $2200 \mathrm{uF}$ \\
& Battery voltage in V & $48 \mathrm{~V}$ \\
& Rated capacity (Ah) & 500 \\
& Initial SOC \% & $50 \%$ \\
\hline
\end{tabular}

\subsection{Block diagram of proposed system}

\subsubsection{Operation of proposed method}

Figure 2 shows the complete block diagram of the proposed test system. The control schemes of UPQC comprises of shunt active power filter (APF) and dynamic voltage restorer (DVR) with a common DC link capacitor. APF regulator estimate the load voltages and currents, capacitor voltage and injected currents. The regulator algorithm of APF developments the measured values and initiates the needed reimbursement signals which is then equated in hysteresis controller to generate the needed gate signals. DVR controller quantifies the supply voltages to produce the required reimbursement and sag/swell recognition signals. These signals are then equated in PWM controller and the needed gate signals are produced. The PV system used as DC grid. In existing UPQC device, conventional proportional integral (PI) controller balances the actual DC link voltage for all operating conditions but it fails to balance the DC link voltage during dynamic as well as high voltage drop conditions [29]-[31].

In this paper to overcome this drawback, an adaptive neuro fuzzy inference system (ANFIS) is used which comprises of both fuzzy system and neural network learning. ANFIS has the potentiality to grasp, recall and take decision [32]. In the proposed work, ANFIS is trained to function as reference DC link voltage estimator and DC link voltage controller. The control strategy change can make the PV to be used as the islanded mode source of power. Table 1 shows the details of the transformers, loads, BESS and solar PV array.

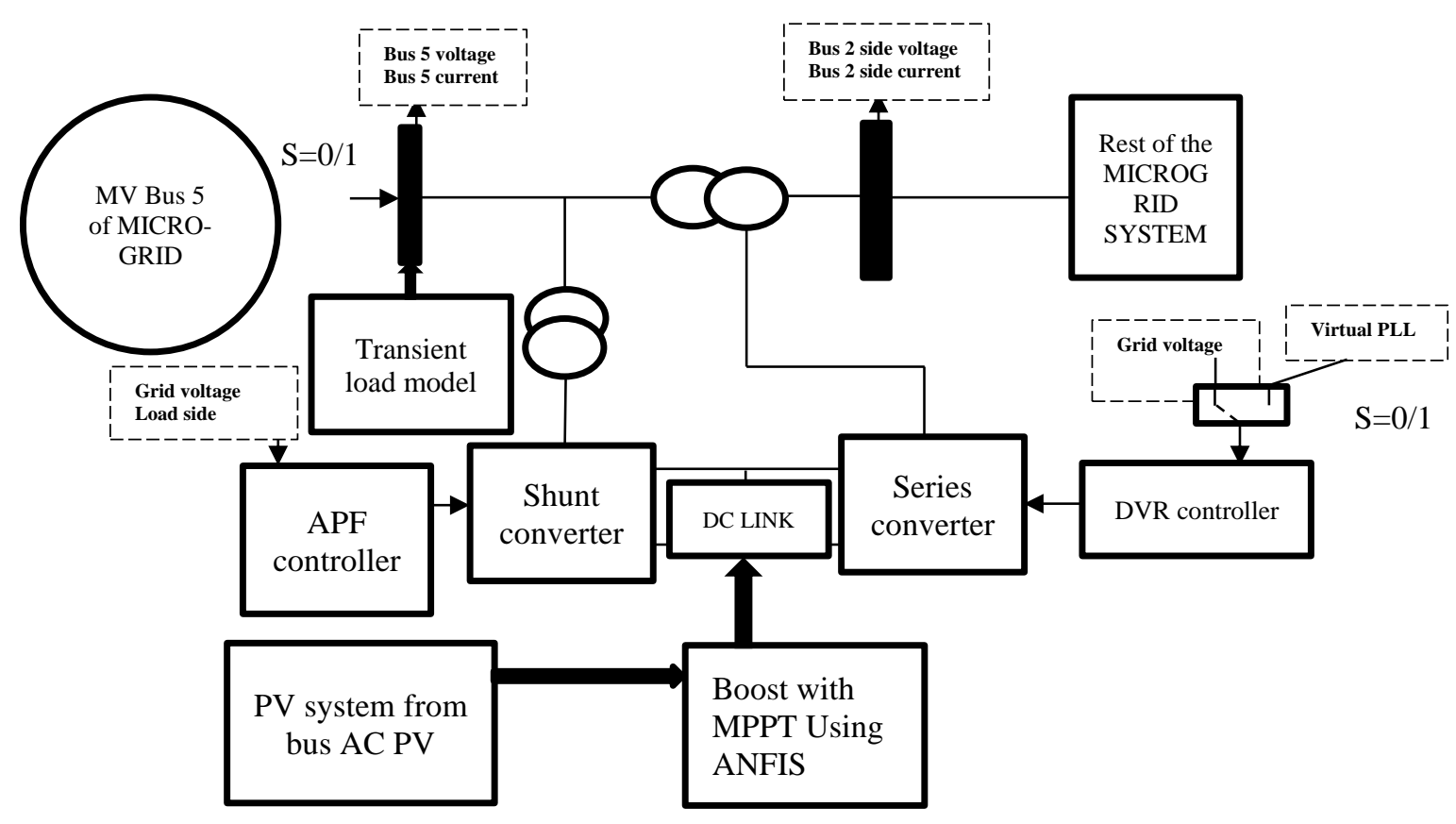

Figure 2. Block diagram of proposed test system 


\subsubsection{ANFIS control in UPQC}

Controller is the heart of any dynamical system which takes care of any interruption in the plant and resumes the system to its initial state in a span of second. The controller aims in modelling and feedback control of dynamic system. The design of the controller using the ANFIS scheme requires a mathematical model of the control plant along with the controller, which can be further used for simulation purposes. The block diagram of the developed controller is shown in Figure 3 and its MATLAB implementation is shown in Figure 4. Inputs to the ANFIS controller, i.e., the error and the change in error, are modeled using equations as follow:

$$
\begin{aligned}
& e(k)=V_{d c}^{*}-V_{d c} \\
& \Delta e(k)=e(k)-e(k-1)
\end{aligned}
$$

where

Vdc ref $=$ the reference voltage,

$\mathrm{Vdc}=$ the actual voltage,

$\mathrm{e}(\mathrm{k})=$ the error and

$\Delta \mathrm{e}(\mathrm{k})=$ the change in error.

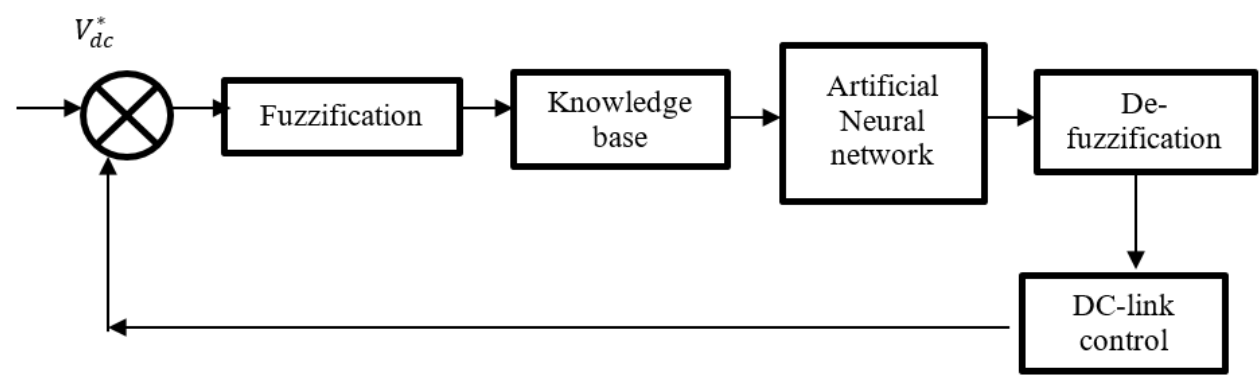

Figure 3. ANFIS implementation

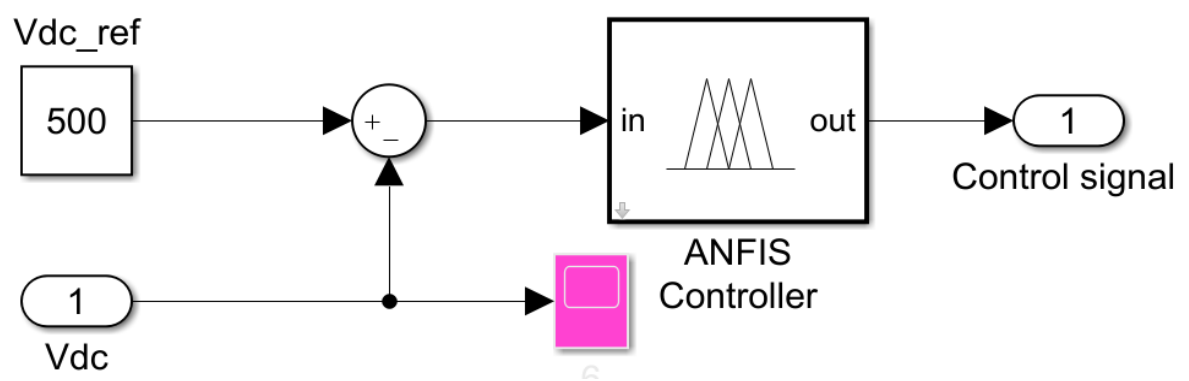

Figure 4. ANFIS MATLAB implementation

A set of 25 rules is written based on the earlier experience or previous knowledge. The input to the rule-based block is taken from the fuzzification unit which transforms crisp data into linguistic variables, which in turn is connected to the neural network block. So as to select appropriate set of rule base Backpropagation algorithm is used for $\mathrm{NN}$ training. To establish the control signal, training is a crucial step which involves making proper selection of the rule base. Once the appropriate rules are fixed and fired, the control signal required to obtain the optimal outputs is generated. The inputs are fuzzified using the fuzzy sets and are given as input to the ANFIS controller, which was used for Mamdani-based FLC and TS-based FLC for decision-making purposes, the same is used in this paper for decision making as well as to design the ANFIS controller. For control purpose the similar set of 25 rules are used in this paper which are not indicated here for the purpose of convenience. The inference involves a set of rules for determining the output decisions. The Figure 5 (see in appendix) shows the simulation diagram of the microgrid test system connected with UPQC which is controlled with ANFIS. 


\section{RESULTS AND DISCUSSION}

The load pattern used in the simulation over the time $0.35 \mathrm{sec}$ is given in Figure 6 . In initial condition load is less and then reaches peak then drops to the lower value. Then the Figure 7 shows the voltage amplitudes and unbalancing voltage deviation (ADVS) of all the buses before connecting the UPQC. It can be seen that the A phase has 0.04619 deviation B-phase has 0.032761 pu and C phase has 0.042813 pu.

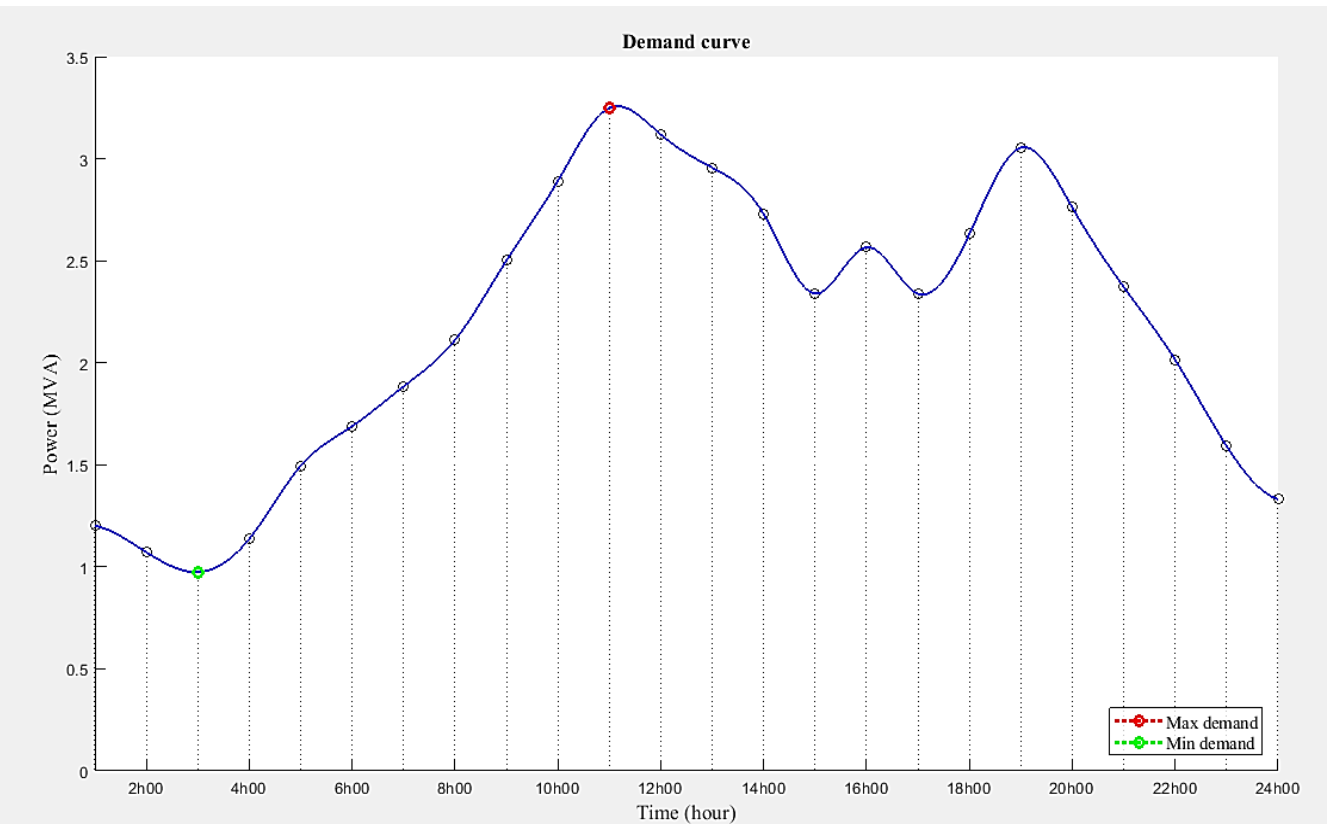

Figure 6. Load pattern of the test system

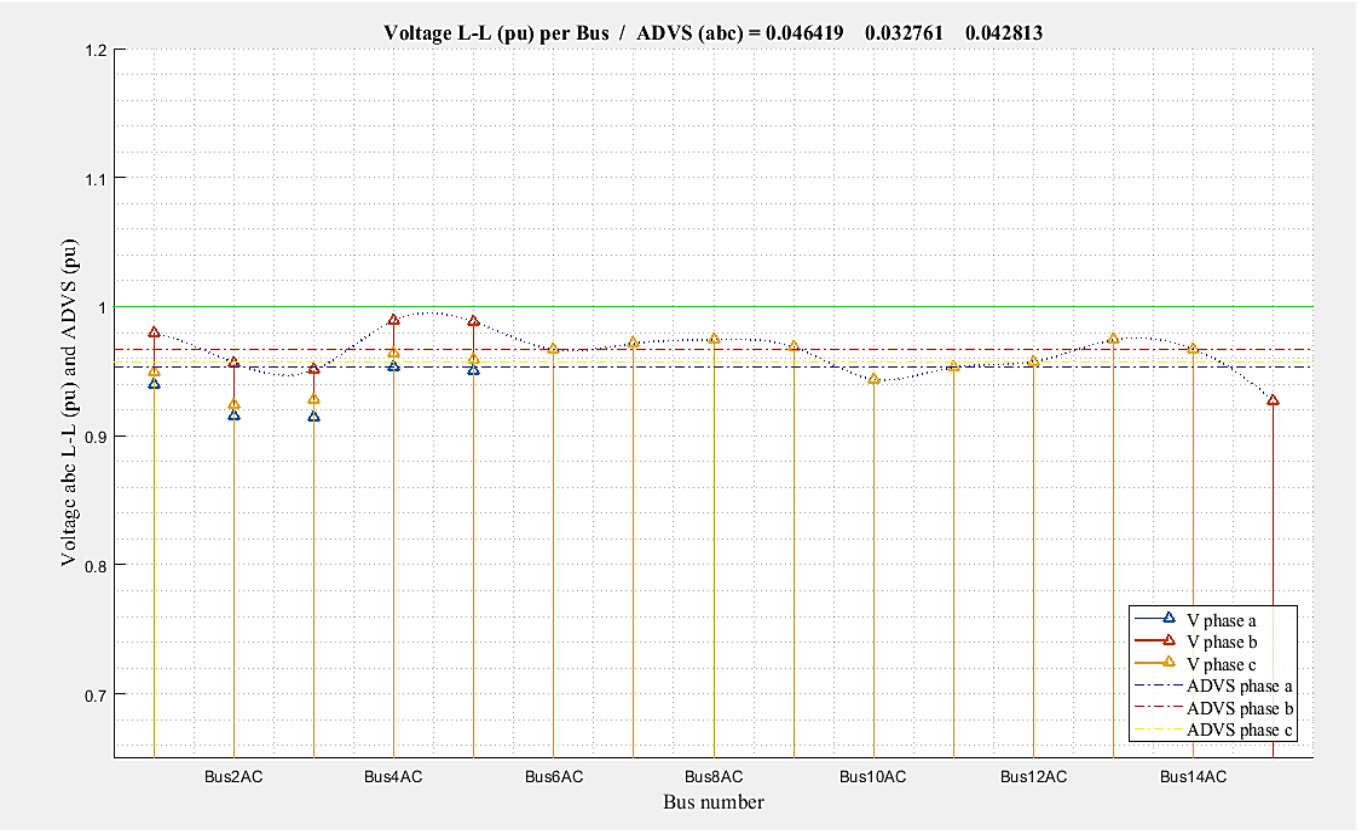

Figure 7. Voltage amplitudes and unbalancing voltage deviation (ADVS) of all the buses

Then the Figure 8 shows the power factor at each bus before connecting the UPQC. It can be seen that bus 2 and 9 are unity power factor. Where other busses have less than 0.85 power factor. Figure 9 shows the voltage amplitudes and unbalancing voltage deviation (ADVS) of all the buses after connecting UPQC- 
ANFIS control. It can be seen that after connecting UPQC the A phase has 0.043969 deviation B-phase has $0.030103 \mathrm{pu}$ and $\mathrm{C}$ phase has $0.040229 \mathrm{pu}$. So, the values of deviation of unbalancing is reduced.

The Figure 10 shows the Power factor at each bus after connecting UPQC-ANFIS control. It can be seen that the power factor got improved in bus 3 and 4 above 0.86 . Other busses are not affected by the UPQC. The bus 5 power factor is reduced because the UPQC supplies the reactive power required to the other buses also. Total harmonic distortion (THD) values in each phase and buses is as shown in Figure 11 and the values are tabulated in Table 2. From the tabulated values in Table 2 it is clear that THD values are within the limits.

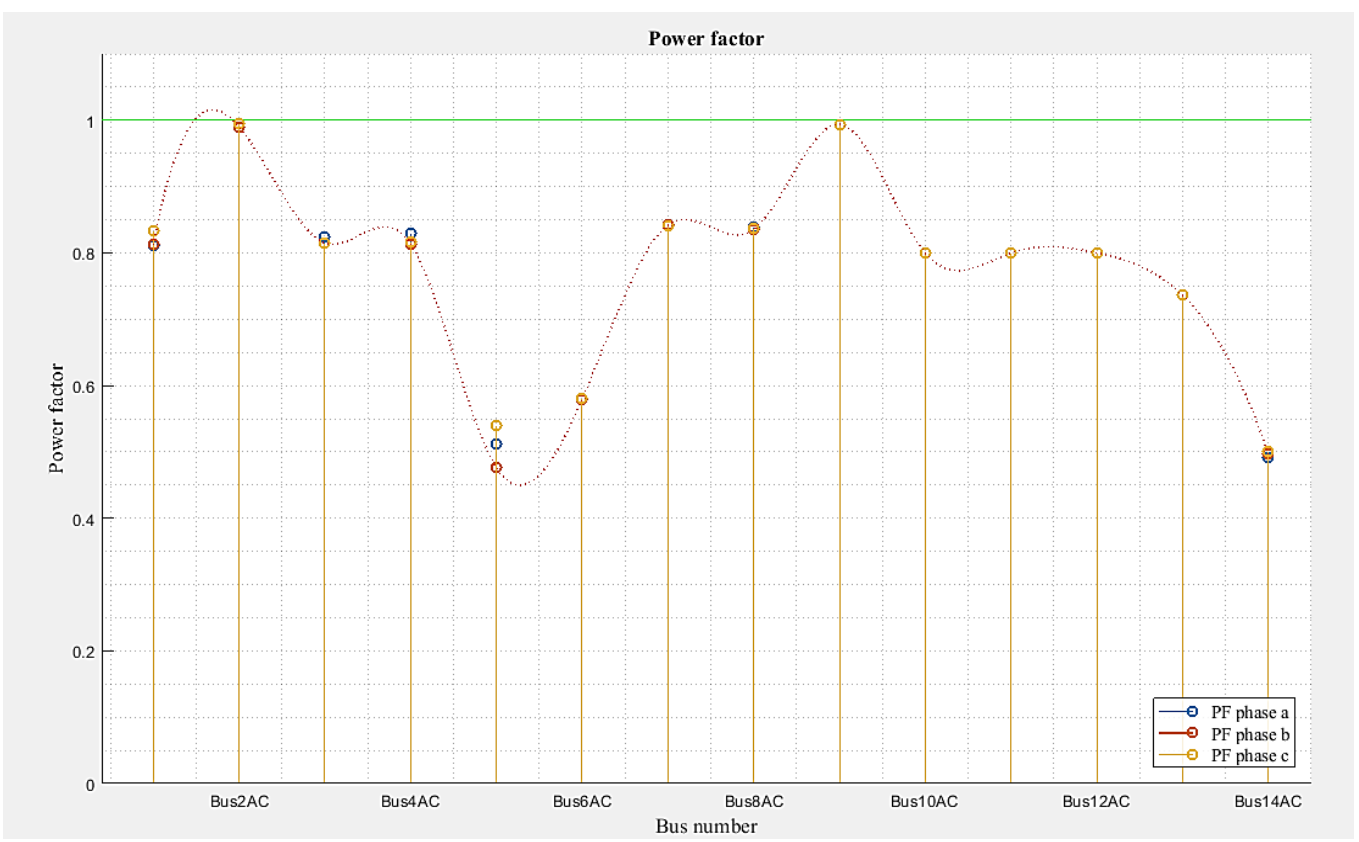

Figure 8. Power factor at each bus

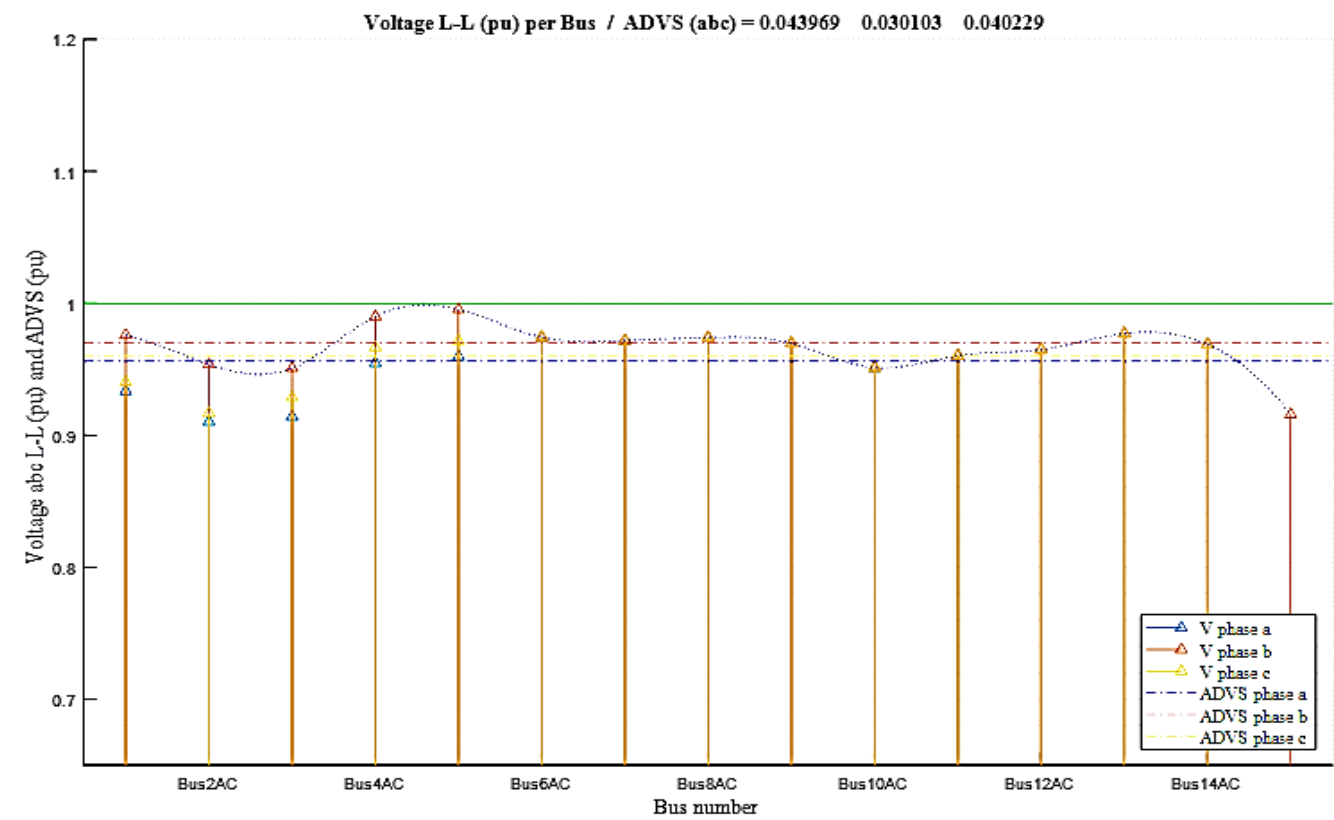

Figure 9. Voltage amplitudes and unbalancing voltage deviation (ADVS) of all the buses after connecting UPQC-ANFIS control 


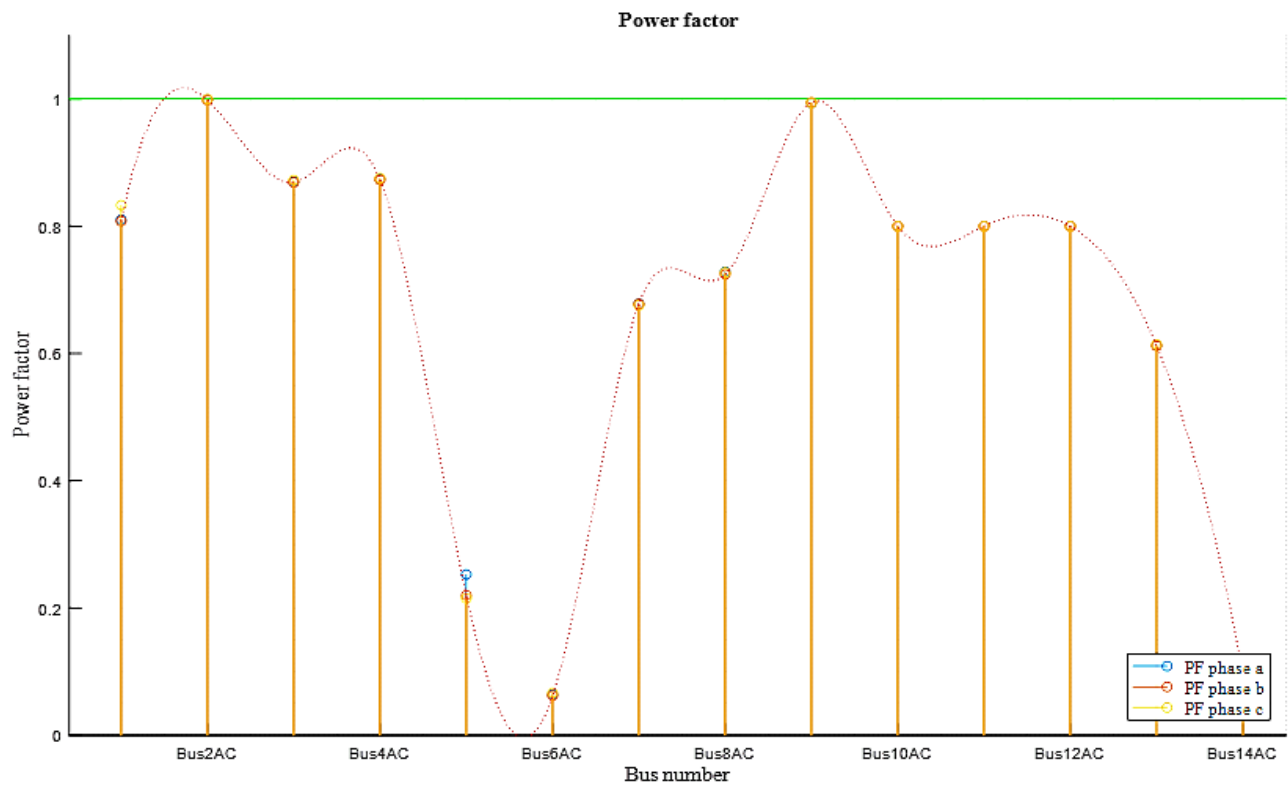

Figure 10. Power factor at each bus after connecting UPQC-ANFIS control

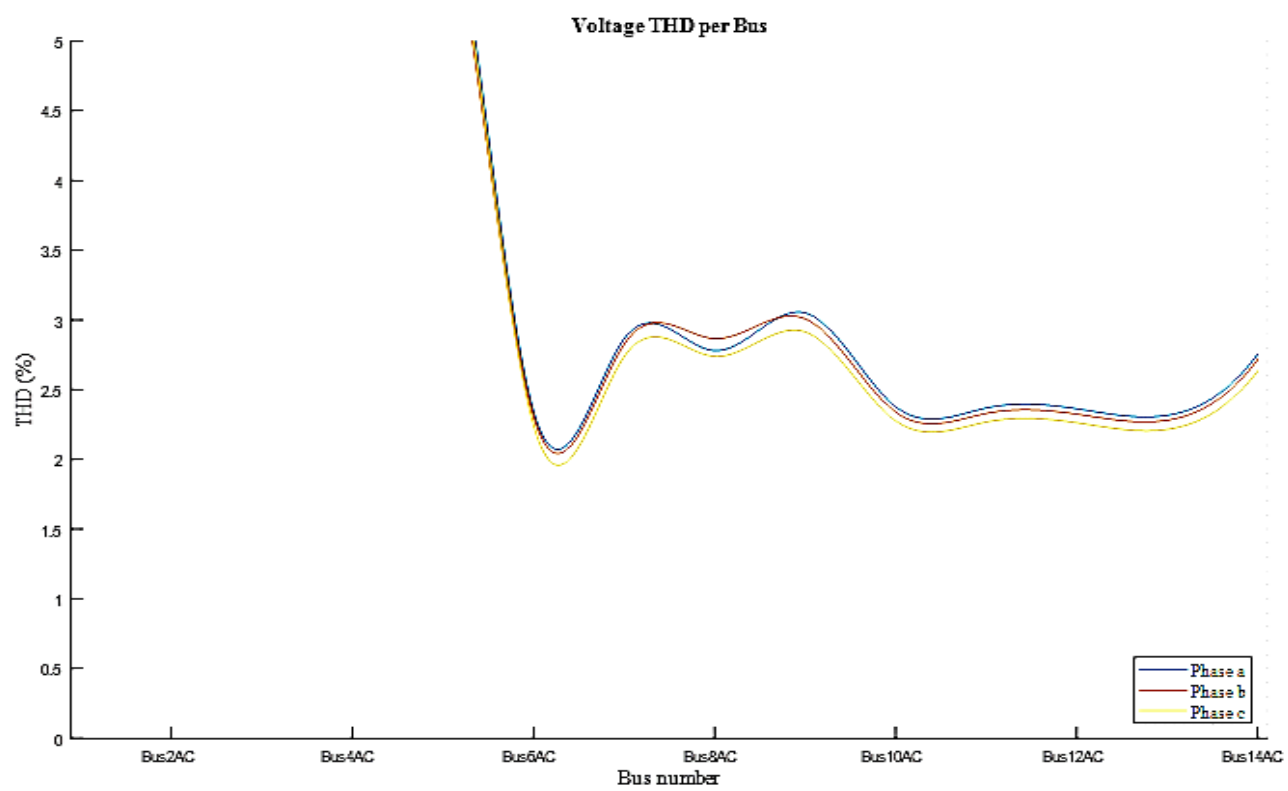

Figure 11. THD values after connecting UPQC-ANFIS control

Table 2. Total harmonic distortion (THD) values in each phase and buses

\begin{tabular}{cccc} 
Bus .No & $\begin{array}{c}\text { THD Values in each phase and buses } \\
\text { Phase A }\end{array}$ & $\begin{array}{c}\text { Phase B } \\
\text { Phase C }\end{array}$ \\
\hline 2 & 5.04 & 5.04 & 5.05 \\
3 & 5.02 & 5.03 & 5.04 \\
4 & 5.01 & 5.01 & 5.02 \\
5 & 5.01 & 5.01 & 5.02 \\
6 & 2.1 & 2.2 & 2.05 \\
7 & 2.7 & 2.8 & 2.6 \\
8 & 2.7 & 2.8 & 2.6 \\
9 & 2.7 & 2.8 & 2.6 \\
10 & 2.25 & 2.3 & 2.4 \\
11 & 2.3 & 2.4 & 2.5 \\
12 & 2.25 & 2.3 & 2.4 \\
13 & 2.25 & 2.3 & 2.4 \\
14 & 2.7 & 2.8 & 2.6 \\
\hline
\end{tabular}




\section{CONCLUSION}

The standard microgrid is used here for the validation of the UPQC powered by PV and the control is done with ANFIS controller. In this paper a Simulink model of standard microgrid is developed and is analyzed for different load pattern. The result shows that the voltage sag and swell in the proposed system is compensated well by the ANFIS controller used in the UPQC. The bus number 2 is selected for UPQC placement because it has the voltage of $220 \mathrm{~V}$ and also power quality problems occurs at the distribution point. Here the UPQC is performing well with the ANFIS controller by improving the power factor and compensating the reactive power, sag and swell. And also, this reduces the peak current taken by the microgrid. The high spiking of PV solar generation results in deterioration of power factor in the distribution side. It is observed from the result that the power factor and THD is improved, also within limits given in IEEE-519 standard. So, a huge impact is created in the standard micro grid after the implementation of UPQC with ANFIS controller.

\section{APPENDIX}

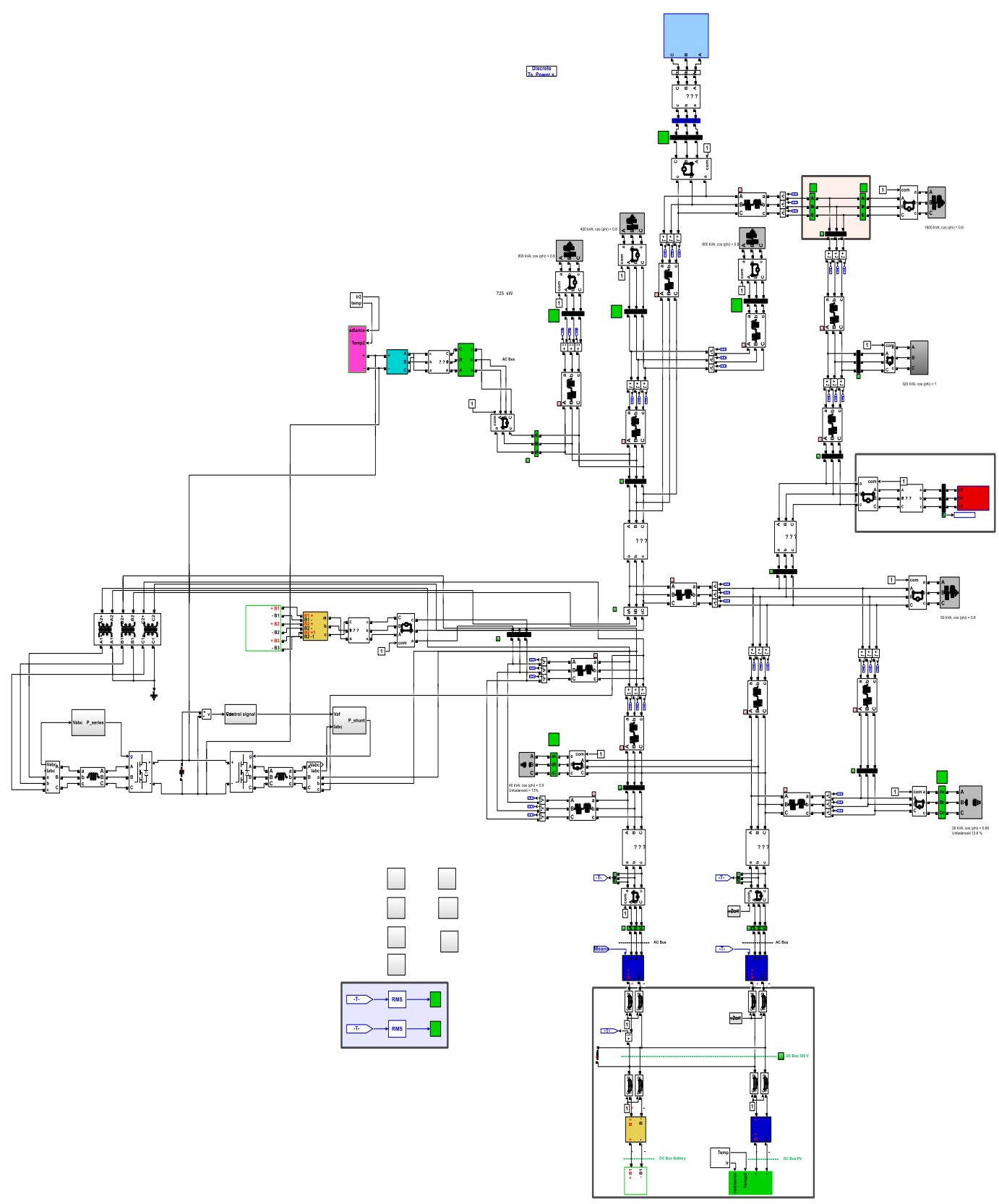

Figure 5. Microgrid test system of [31] after including UPQC 


\section{REFERENCES}

[1] S. Paramanik, K. Sarker, D. Chatterjee, and S. K Goswami, "Smart grid power quality improvement using modified UPQC," 2019 Devices for Integrated Circuit (DevIC), Kalyani, India, 2019, pp. 356-360, doi: 10.1109/DEVIC.2019.8783704.

[2] J. Ye, H. B. Gooi, X. Zhang, B. Wang, and U. Manandhar, "Two-level algorithm for UPQC considering power electronic converters and transformers," IEEE Applied Power Electronics Conference and Exposition (APEC), Anaheim, CA, USA, 2019, pp. 3461-3467, doi: 10.1109/APEC.2019.8722007.

[3] J. Wang, H. Wu, K. Sun, and L. Zhang, "A high efficiency quasi-single-stage unified power quality conditioner integrating distributed generation," IEEE 10th International Symposium on Power Electronics for Distributed Generation Systems (PEDG), Xi'an, China, 2019, pp. 1099-1104, doi: 10.1109/PEDG.2019.8807481.

[4] C. K. Sundarabalan, Y. Puttagunta, and V. Vignesh, "Fuel cell integrated unified power quality conditioner for voltage and current reparation in four-wire distribution grid," IET Smart Grid, vol. 2, no. 1, pp. 60-68, 2019, doi: 10.1049/iet-stg.2018.0148.

[5] A. K. Karmaker, S. Roy, and M. R. Ahmed, "Analysis of the impact of electric vehicle charging station on power quality issues," International Conference on Electrical, Computer and Communication Engineering (ECCE), Cox'sBazar, Bangladesh, 2019, pp. 1-6, doi: 10.1109/ECACE.2019.8679164.

[6] L. Zhang, X. Zhang, D. Li, and H. Tan, "Research on power quality control method of V2G system of electric vehicle based on APF," International Conference on Advanced Mechatronic Systems (ICAMechS), Kusatsu, Shiga, Japan, 2019, pp. 186-189, doi: 10.1109/ICAMechS.2019.8861642.

[7] S. Faddel, A. Elsayed, T. A. Youssef, and O. Mohammed, "Experimental verification of the effect of uncoordinated charging of electric vehicles on power grids," IEEE Power and Energy Society Innovative Smart Grid Technologies Conference (ISGT), Washington, DC, USA, 2019, pp. 1-4, doi: 10.1109/ISGT.2019.8791580.

[8] F. Li, L. Guo, L. Liu, X. Li, and Q. Wang, "Method to improve charging power quality of electric vehicles," The Journal of Engineering, vol. 2019, no. 16, pp. 2706-2709, 2019, doi:10.1049/joe.2018.8544.

[9] U. Sharma and B. Singh, "A generalised double integral sliding mode control for bidirectional charger of light electric vehicle," IEEE International Conference on Environment and Electrical Engineering and 2019 IEEE Industrial and Commercial Power Systems Europe (EEEIC/I\&CPS Europe), Genova, Italy, 2019, pp. 1-6, doi: 10.1109/EEEIC.2019.8783407.

[10] D. E. Olivares et al., "Trends in microgrid control," IEEE Transactions on smart grid, vol. 5, no. 4, pp. 1905-1919, Jul. 2014, doi: 10.1109/TSG.2013.2295514.

[11] H. A. Gabbar, "Smart energy grid engineering," Academic Press, 2017, doi: 10.1016/C2015-0-04708-6.

[12] A. Dimeas, A. Tsikalakis, G. Kariniotakis, and G. Korres, "Microgrids control issues," in Microgrids: Architectures and Control, Wiley-IEEE Press, 2014

[13] E. Planas, J. Andreu, J. I. G_arate, I. M. De Alegría, and E. Ibarra, "AC and DC technology in microgrids: a review," Renew. Sustain. Energy Rev., vol. 43, pp. 726-749, Mar. 2015, doi: 10.1016/j.rser.2014.11.067.

[14] L. Jia, Y. Zhu, and Y. Wang, "Architecture design for new AC-DC hybrid microgrid," IEEE 1st Int. Conf. Direct Curr. Microgrids (ICDCM), 2015, pp. 113-118, doi: 10.1109/ICDCM.2015.7152020.

[15] S. Parhizi, H. Lotfi, A. Khodaei, and S. Bahramirad, "State of the art in research on microgrids: a review," IEEE Access, vol. 3, pp. 890-925, 2015, doi: 10.1109/ACCESS.2015.2443119.

[16] F. Martin-Martínez, A. Sanchez-Miralles, and M. Rivier, "A literature review of microgrids: a functional layer-based classification," Renew. Sustain. Energy Rev., vol. 62, pp. 1133-1153, 2016, doi: 10.1016/j.rser.2016.05.025.

[17] E. Hossain, E. Kabalci, R. Bayindir, and R. Perez, "Microgrid testbeds around the world: state of art," Energy Convers. Manag, vol. 86, pp. 132-153, 2014, doi: 10.1016/j.enconman.2014.05.012.

[18] G. Turner, J. P. Kelley, C. L. Stom, D. A. Wetz, and W. Lee, "Design and active control of a microgrid testbed," IEEE Trans. Smart Grid., vol. 6, no. 1, pp. 73-81, 2015, doi: 10.1109/TSG.2014.2340376.

[19] M. S. Mahmoud, S. A. Hussain, and M. A. Abido, "Modeling and control of microgrid: An overview," J. Frankl. Inst., vol. 351, no. 5, pp. 2822-2859, 2014, doi: 10.1016/j.jfranklin.2014.01.016.

[20] R. H. Lasseter et al., "CERTS microgrid laboratory test bed," IEEE Trans. Power Deliv., vol. 26, no. 1, pp. 325-332, 2011, doi: 10.1109/TPWRD.2010.2051819.

[21] N. W. A. Lidula and A. D. Rajapakse, "Microgrids research: a review of experimental microgrids and test systems," Renew. Sustain. Energy Rev., vol. 15, no. 1, pp. 186-202, 2011, doi: 10.1016/j.rser.2010.09.041.

[22] P. Piagi and R. H. Lasseter, "Autonomous control of microgrids," IEEE Power Eng. Soc. Gen. Meet., 2006, doi: 10.1109/PES.2006.1708993.

[23] A. Kaur, J. Kaushal, and P. Basak, “A review on microgrid central controller," Renewable and Sustainable Energy Reviews, vol. 55, pp. 338-345, 2016, doi: 10.1016/j.rser.2015.10.141.

[24] M. H. Andishgar, E. Gholipour, and R. A. Hooshmand, "An overview of control approaches of inverter-based microgrids in islanding mode of operation," Renewable and Sustainable Energy Reviews, vol. 80, pp. 1043-1060, 2017, doi: 10.1016/j.rser.2017.05.267.

[25] Y. Yoldas, A. Onen, S. M. Muyeen, A. V. Vasilakos, and I. Alan, "Enhancing smart grid with microgrids: challenges and opportunities," Renew. Sustain. Energy Rev., vol. 72, pp. 205-214, 2017, doi: 10.1016/j.rser.2017.01.064.

[26] J. J. Justo, F. Mwasilu, J. Lee, and J. Jung, "AC-microgrids versus DC-microgrids with distributed energy resources: a review," Renew. Sustain. Energy Rev., vol. 24, pp. 387-405, 2013, doi: 10.1016/j.rser.2013.03.067.

[27] L. Ortiz, R. Orizondo, A. Aguila, J. W. González, G. J. López, and I. Isaac, "Hybrid AC/DC microgrid test system simulation: grid-connected mode," Heliyon, vol. 5, no. 12, 2019, doi: 10.1016/j.heliyon.2019.e02862.

[28] H. Heydari and A. H. Moghadasi, "Optimization scheme in combinatorial UPQC and SFCL using normalized simulated annealing," IEEE Transaction on Power Delivery, vol. 26, no. 3, pp. 1489-1498, 2011, doi: 10.1109/TPWRD.2011.2111390.

[29] V. Khadkikar and A. Chandra, "UPQC-S: A novel concept of simultaneous voltage sag/swell and load reactive power compensations utilizing series inverter of UPQC," IEEE transactions on power electronics, vol. 26, no. 9, pp. 2414-2425, 2011, doi: 10.1109/TPEL.2011.2106222.

[30] V. Khadkikar, A. Chandra, A. O. Barry, and T. D. Nguyen, "Power quality enhancement utilizing single-phase unified power quality conditioner: digital signal processor-based experimental validation," IET Power Electronics, vol. 4, no. 3, pp. 323-331, 2011, doi: 10.1049/iet-pel.2010.0031.

[31] S. S. Dheeban and N. B. M. Selvan, "PV integrated UPQC for sensitive load," Int. Conference on Emerging Trends in Information Technology and Engineering (ic-ETITE), 2020, pp. 1-7, doi: 10.1109/ic-ETITE47903.2020.330.

[32] S. S. Dheeban and N. B. M. Selvan, "ANFIS-based power quality improvement by photovoltaic integrated UPQC at distribution system," IETE Journal of Research, pp. 1-19, 2021, doi: 10.1080/03772063.2021.1888325. 


\section{BIOGRAPHIES OF AUTHORS}

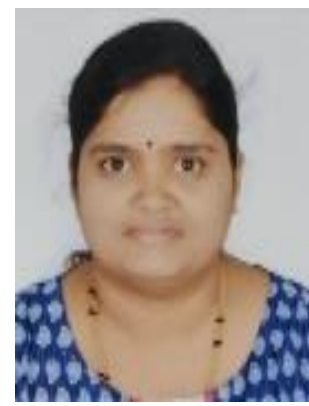

Sumana S ID Bd SC P is currently working as Assistant professor in the department of Electrical and Electronics Engineering, Dayananda sagar College of Engineering, Bengaluru. She has published papers in national and international conferences. Her area of intrest is Power system, Power quality and Power electriletronics. She is pursuing $\mathrm{Ph}$. D in the area of Power quality. She can be contacted at email: Email: sumana-eee@dayanandasagar.edu.

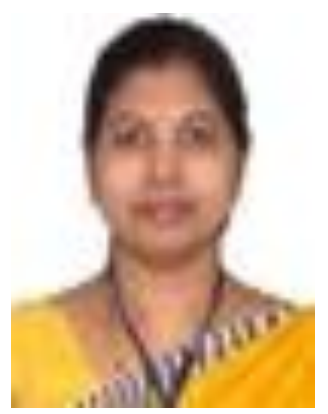

Dhanalakshmi R (iD) SI SC P currently working as professor in the department of Electrical and Electronics Engineering at Dayanandasagar College of Engineering, Bengaluru.Her area of interest is Power system, Power electronics and renewable energy sources. She has many publications in reputed journals. She can be contacted at email: Email: dhanalakshmieee@ dayanandasagar.edu.

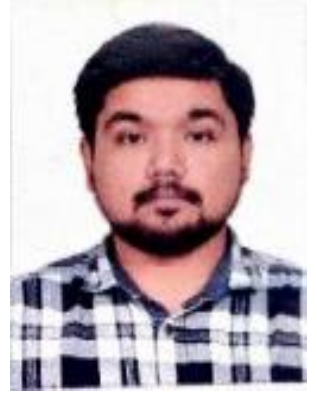

Dhamodharan S (D) 8 S $P$ currently working as R\&D manager in the division of Elecrtical and Electronics at ViswaJothi Technologies Pvt LTD, Bangalore. His area of interest is power electronics, power system, pluging electric vehicles with renewable energy resource. He is persuing part time Ph.D in the area of Electric Vehicle charging. He can be contacted at email: Email: dhamu.winner@gmail.com. 